\title{
ФОРМИРОВАНИЕ ИНОЯЗЫЧНОЙ ЛЕКСИЧЕСКОЙ КОМПЕТЕНЦИИ В УСЛОВИЯХ ЧЕЧЕНСКО-РУССКОГО БИЛИНГВИЗМА
}

\section{FORMATION OF FOREIGN LANGUAGE LEXICAL COMPETENCE IN THE CONDITIONS OF CHECHEN-RUSSIAN BILINGUALISM}

\section{T. Abdukadyrova}

Summary: In the process of learning foreign languages, the use of the native language is an effective methodological support for students. The native language motivates students' cognitive and communicative activities, helping them to achieve success in learning a foreign language. Chechen-Russian bilingualism has created the necessary conditions for the development of methodological tools for the formation of a mechanism for switching bilinguals from one language to another. The trilingual (German-Russian-Chechen) dictionary helps to consolidate links in the interaction of three languages German, Russian and Chechen. The use of trilingual dictionaries of teaching a foreign language allows students to successfully overcome interference, which helps motivate students to learn their native, Russian and foreign languages.

Keywords: german-russian-chechen trilingual dictionary, chechenrussian bilingualism, bilingual, interference, bilingual space.
K ак известно Россия входит в число стран с самым высоким в мире языковым многообразием, в настоящее время население нашей страны использует около 100 языков коренных народов. В то же время лишь третья часть из них используется в качестве языка обучения[5, с.7].

Для большинства нерусских народов России, и народа Чеченской Республики в том числе, национально - русский билингвизм является неизбежностью, так как на территории всей страны русский язык - общегосударственный.

Проблема обучения иностранным языкам в билингвальной и даже полилингвальной аудитории - один из наиболее актуальных вопросов в современной лингводидактике. Вопрос о билингвизме достаточно отражен в исследованиях отечественных и зарубежных авторов, Ю.Д. Дешериева, Н.В Барышникова, М. Колкер, Р.К. Миньяр-Белоручева, М.Р. Овхадова, А.Ж. Махмудовой и других хотя и распространен не менее, но изучен недостаточно, особенно в районах с преобладанием коренного населения.

\author{
Абдукадырова Тумиша Таштиевна, \\ к.п.н., дочент, Чеченский государственный университет \\ tumischa-uni@mail.ru
}

Аннотация: Чеченско-русский билингвизм создал необходимые условия разработки методического инструментария для формирования механизма перехода билингвов с одного языка на другой.

Трехъязычный (немецко-русско-чеченский) словарь способствует укреплению взаимосвязи между языками - немецким, русским и чеченским.

Использование трехъязычных словарей обучении иностранному языку позволяет обучающимся успешно преодолеть интерференцию, что способствует мотивации обучающихся к изучению родного, русского и иностранного языков.

Ключевые слова: чеченско-русский билингвизм, методический инструментарий, билингв, интерференция, билингвальное пространство.

Чеченско-русский билингвизм интересен также тем, что при рассмотрении его в трех плоскостях - языковой, культурной и религиозной - мы обнаруживаем разнополярье языковых семей, культур и вероисповеданий. Поликультурная пестрота отражается через призму элементов исламской и христианской религий, основ вайнахского этикета и славянской культуры. Следовательно, необходимо учитывать уникальность этого феномена при обучении иностранным языкам и культурам, так как по словам С.Г. Тер-Минасовой «понятие языковой и культурной картин мира играет важную роль в изучении иностранных языков» [11, с.84].

Следует отметить, что процесс обучения иностранному языку и культуре в билингвокультурной аудитории, представленной чеченскими учащимися, имеет целый ряд психологических, социокультурных, лингводидактических особенностей, учёт которых необходим в практике преподавания. Следовательно, для более эффективного обучения чеченских школьников иностранному языку необходимо определить тип билингвизма в данных сложившихся условиях.

Определяя тип билингвизма в анализируемых усло- 
виях, мы приходим к выводу о том, что чеченским учащимся присущ репродуктивный билингвизм, поскольку они могут воспроизводить речевые произведения, принадлежащие вторичной языковой системе, но не могут порождать их, то есть не могут порождать речевые произведения на русском языке на достаточном уровне для осуществления коммуникации [3, с.12].

Следует также отметить, что в Чеченской Республике в связи с известными событиями конца XX - XXI веков преобладает коренное население (чеченцы). Отсутствие внимания к естественному билингвизму школьников, использование методик и средств обучения, применяемых для носителей русского языка (монолингвов), а также недостаточный учет этнических характеристик обучаемых являются причиной низкой результативности обучения иностранным языкам, о чем свидетельствуют, к примеру, результаты ОГЭ и ЕГЭ выпускников Чеченской Республики по английскому и немецкому языкам.

В учебных планах школ Чеченской Республики всех типов родной язык значится как основной предмет. Поэтому большинство учащихся средних школ нашей республики билингвальны и знание двух языков - чеченского и русского - составляет тот фон, на основе которого начинается обучение иностранному языку, образуя, таким образом, триглоссию/триязычие или трилингвизм, термины, которые рассматриваются большинством специалистов, как синонимы [9, с.84].

Трилингвизм - достаточно сложный речевой феномен, в котором контактируют три языка. К началу изучения иностранного языка навыки использования национального и русского языков в повседневной жизни учащихся являются прочно установившимися, они оказывают влияние на овладение третьим по порядку языком.

Можно характеризовать трилингвизм как уверенное владение родным языком, умение общаться, читать, писать на втором языке, и умение осуществлять определенную коммуникацию на иностранном языке. Третий изучаемый язык «становится компонентом трилингвизма не с момента начала его изучения, а с момента достижения учащимися известного уровня владения» третьим языком $[5$, с.8].

Используя определение Н.В. Барышникова, мы считаем искусственным трилингвом «того человека, который кроме своего родного языка не в сравнимой степени, но компетентен в двух языках, способен при необходимости на коммуникативно достаточном уровне пользоваться тем или иным из них последовательно или попеременно» $[5$, с.9] .

Реализация процесса достижения необходимого уровня владения лексикой иностранного языка в усло- виях билингвизма сопровождается дополнительными трудностями, проявляющимися вследствие взаимодействия лексических систем контактирующих языков.

Особенности обучения иностранным языкам в билингвальных условиях проявляются в настоящее время в следующих факторах:

- отсутствие программ и учебников, отражающих региональные, национальные, этнокультурные особенности обучающихся;

- несоблюдение принципов, учитывающих специфику обучения в условиях естественного билингвизма;

- несоблюдение принципа учета родного языка при изучении иностранных языков.

- В следствие проведенного нами (на примере немецкого языка) анализа выявлены нарушения употребления лексических единиц немецкого языка на фонетическом уровне, в результате чего определились следующие тенденции:

- учащиеся -билингвы используют фонетические признаки чеченского и русского языков;

- фонетические правила иностранного языка (немецкого, английского) усваиваются достаточно медленно, что вызвано интерференцией чеченского и русского фонетических строев;

- структурная сложность фонетического строя языка не получает полного освоения, что определяется тенденцией к редуцированию правил и опоре на фонетику чеченского и русского языков.

Действительно, владение словом иностранного языка - сложное комплексное умение. Обучение иноязычной лексике особенно в билингвальной аудитории должно быть направлено на предупреждение затруднений, основанных на недостаточной дифференциации тех аспектов лексической единицы, которые не совпадают.

Формирование качественных характеристик владения иноязычной лексикой в условиях чеченско-русского двуязычия осложняется межъязыковой интерференцией контактирующих языков, вследствие которой появляются многочисленные трудности. По нашему мнению, для предупреждения имеющих место затруднений важно предусмотреть специальные приемы, сокращающие отрицательное влияние лексических систем чеченского и русского языков на формирующуюся иноязычную лексическую компетенцию учащихся.

В школах Чеченской Республики нами была определена методическая стратегия обучения иностранному языку (немецкому) по определению типа билингвизма учащихся на основании результатов опроса школьников и учителей. Как было отмечено выше «..условия обучения иностранным языкам в общеобразовательной школе в Чеченской республике позволили нам определить 
билингвальное состояние обучающихся. Мы пришли к выводу о том, что учащиеся Чеченской республики обладают репродуктивным (по числу усвоенных действий, выполняемых на основе умения), чистым (по соотнесению речевых механизмов), опосредованным (по связи с мышлением), субординативным (по характеру взаимодействия контактирующих языков в сознании учащегося), близким к искусственному (по условиям формирования) типом билингвизма...» [3, с.19].

Данное обстоятельство объясняет наличие трудностей в процессе формирования билингвальной языковой личности, изучающих более трех языков. Условия обучения в школах Чеченской республики можно назвать уникальными. Обучение всем предметам в школах осуществляется на русском языке, а билингвальное состояние обучающихся (плохое владение русским языком) является препятствием для эффективного овладения предметными знаниями. В процессе обучения иностранному языку используются учебники федерального перечня, в которых пояснения, комментарии, переводные упражнения, базовый словарь даны на русском языке, что исключает опору на родной чеченский язык. Русский язык, являясь языком обучения, в то же время является языком - посредником между родным и немецким языком в овладении последним. В этих условиях следует признать, что «речевые навыки на родном языке оказывают непосредственное влияние на усвоение немецкого языка. Родной язык как доминирующий оказывает влияние на усвоение иностранного языка, как на продуктивном, так и на репродуктивном уровнях» [3, c.129].

Встает вопрос о разработке методического инструментария, разработанного с учетом принципов билингвизма, и который может быть использован в процессе обучения иностранному языку. Таким инструментарием может стать трехъязычный (немецко-русско-чеченский) словарь, разработанный нами на примере абстрактной лексики немецкого, русского и чеченского языков, так как на практике, чеченские обучающиеся испытывают большие трудности в обучении иноязычной абстрактной лексике.

\section{Приведем несколько примеров.}

В трехъязычном словаре абстрактной лексики употребление слов демонстрируется в контексте предложений на трех языках. Первое место занимает изучаемый иностранный язык (немецкий), второе место занимает русский язык, поскольку обучение ведется на русском языке и третье место занимает родной чеченский язык. Например, словарная статья со словом die Ablenkung развлечение и его синонимами:

1. Er sucht Ablenkung.

Он ищет развлечений.

Иза самукъадоккхург лоьхуш ву.

\section{Ich suche Zerstreunung.}

Я ищу развлечений.

Со самукъадолу хІума лоьхуш ву.

В данном случае учащиеся могут наблюдать совпадение в двух языках - в чеченском и русском, когда во всех трех случаях употребляется одно и то же слово развлечение - самукхъадаккхар, самукъадалар, тогда как в немецком языке в трех предложениях употребляются разные абстрактные лексические единицы: die Ablenkung, die Zerstrenung.

При сопоставлении трех языков учащийся приходит к выводу о том, что одно значение, которое в родном языке выражается одним словом, в немецком языке может быть выражено несколькими разными словами.

Приведем еще один пример употребления немецкого слова das Muster. Немецкое слово das Muster - означает образеи, образеи (для подражания), образец (узор). В данном случае наблюдается частичное совпадение немецкого и русского языков и несовпадение с чеченским языком.

Каждая абстрактная лексическая единица имеет несколько значений, и они не могут быть продемонстрированы с помощью визуального материала, поэтому существенно важное значение имеет параллельное представление материала на немецком, чеченском и русском языках.

Например: абстрактная лексическая единица die Auffassung имеет следующие значения: точка зрения, понимание, мнение. Эти значения демонстрируются в следующих примерах:

Ich lehne diese Auffasung ab.(нем. яз.)

Я не согласен с этой точкой зрения. (рус.яз.)

Хьан ойланца со реза вач.(чеч.яз.)

Das ist eine richtige (falsche) Auffassung.(нем. яз.)

Это (не) правильное понимание. (рус.яз.)

Иза нийса кхетар (цакхетар) ду. (чеч.яз.)

Ich teile deine Auffassung. (нем. яз.)

Я разделяю твое мнение. (рус.яз.)

Хьуна хетарг сунахета а! (чеч.яз.)

При построении трехъязычного словаря учитывался принцип изучения языков и культур, который предполагает демонстрацию неразрывной связи языка и культуры, в данном случае языкового явления и культуры его употребления в разных языках (немецком, русском, чеченском). Для воплощения этого принципа вся работа от презентации абстрактной единицы до вариантов ее употребления сопровождается сопоставлением с соответствующей культурой.

Представляем примерный фрагмент трехъязычного (немецко-русско-чеченского) словаря абстрактной лек- 
сики (Таблица 1).

Результаты, полученные в процессе экспериментального обучения, подтвердили сформулированную гипотезу исследования о том, что обучение немецкой абстрактной лексике в условиях чеченско-русского билингвизма будет более эффективным, если оно осуществляется с использованием специально разработанного трехъязычного методического инструментария (немецко-русско-чеченского словаря [4, с.136].

Обучение иностранному языку на основе уже имеющегося филологического опыта обучающихся в родном и русском языках способствует расширению их лингви- стического мировоззрения, повышает интерес к изучению языков, позволяет быть способными осуществлять коммуникативную деятельность в полилингвальной среде.

Исходя из вышесказанного следует добавить, что применение трехъязычных словарей в процессе обучения иностранному языку и выполнение упражнений и заданий с их использованием, по нашему мнению, будет способствовать не только формированию механизма билингвизма, преодолению интерференции, но и вызовет интерес учащихся к изучению родного, русского и иностранного языков, поскольку поможет им преодолевать языковые трудности в любой полилингвальной среде.

Фрагмент трехъязычного (немецко-русско-чеченского) словаря абстрактной лексики

Таблица 1.

\begin{tabular}{|c|c|c|}
\hline Немецкий язык & Русский язык & Чеченский язык \\
\hline $\begin{array}{l}\text { - Das steht nicht in meiner Macht. } \\
\text { - Durch die Macht der Umstände bin ich gezwungen. }\end{array}$ & $\begin{array}{l}\text { - Это не в моих силах. } \\
\text { - Я вынужден в силу обстоятельств. }\end{array}$ & $\begin{array}{l}\text { - Иза дан сан ницкъ бац. } \\
\text { - ТІехІоьттинчу хьолех со } \\
\text { деекхарийлахь ву. }\end{array}$ \\
\hline $\begin{array}{l}\text { Die Kraft- } \\
\text { - Das sind ungleiche Kräfte. } \\
\text { - Man muss alle physischen und geistigen Kräften in } \\
\text { Bewegung setzen. }\end{array}$ & $\begin{array}{l}\text { - сила, мощность } \\
\text { - Это неравные силы. } \\
\text { - Надо мобилизовать все физические и духовные силы }\end{array}$ & $\begin{array}{l}\text { - ницкъ, гlopa } \\
\text { - Хьорш цхьатера ницкъеш бац. } \\
\text { - Массо гlора-ницкъ тlетаlo беза. }\end{array}$ \\
\hline $\begin{array}{l}\text { Die Gewalt - } \\
\text { - Mit aller Gewalt. } \\
\text { - mit Gewalt geht es nicht. }\end{array}$ & $\begin{array}{l}\text { - сила (власть) } \\
\text { - Всеми силами. } \\
\text { - Силой ничего не добьёшься. }\end{array}$ & $\begin{array}{l}\text { - ницкъ, Іедал } \\
\text { Ницкъ махьуьллу! } \\
\text { Ницкъонца хІумма дайталур дац. }\end{array}$ \\
\hline $\begin{array}{l}\text { Der Eindruck - } \\
\text { - Ich habe von ihm den Eindruck eines lieben Menschen. } \\
\text { - Wir tauschen unsere Eindrücke aus. } \\
\text { - Diese moderne Stadt hinterlässt } \\
\text { einen schönen Eindruck. } \\
\text { - Unter dem Eindruck des soeben Gehörten. }\end{array}$ & $\begin{array}{l}\text { - впечатление } \\
\text { - Он представляется мне просто милым человеком. } \\
\text { - Мы обмениваемся мнениями. } \\
\text { - Этот современный город } \\
\text { оставляет прекрасное впечатление } \\
\text { - Под впечатлением от только что услышанного. }\end{array}$ & $\begin{array}{l}\text { - битам, битамалла } \\
\text { - Сунна и дика адам хита. } \\
\text {-Тхо тхайн битамаш буьйцуш дара вовшийн. } \\
\text { - Цу гІаланах лаьцна исбаьхьа } \\
\text { битам бисира тхан. } \\
\text { - Со хІинцца хезинчо ецваьккхина. }\end{array}$ \\
\hline $\begin{array}{l}\text { Der Empfang - } \\
\text { - Man bereitete uns einen feierlichen (festlichen, } \\
\text { herzlichen, kalten, warmen) Empfang. }\end{array}$ & $\begin{array}{l}\text { - приём, встреча } \\
\text { - Нам устроили торжественный } \\
\text { (праздничный, сердечный, холодный, тёплый) приём. }\end{array}$ & $\begin{array}{l}\text { - схаэцар, тlеэцар } \\
\text {-Тхо чlorla деза (деза, даггара, } \\
\text { шийла, тlехула, довха) тlеийцира. }\end{array}$ \\
\hline $\begin{array}{l}\text { Der Erfolg - } \\
\text { - Er hat keinen Erfolg im Leben. } \\
\text { - Aber er hatte damit keinen Erfolg. } \\
\text { - Die Premiere war ein Erfolg. } \\
\text { - Ich bin stolz auf deine Erfolge } \\
\end{array}$ & $\begin{array}{l}\text { - yспех } \\
\text { - Он не имеет успеха в жизни. } \\
\text { - Но из этого ничего не вышло. } \\
\text { - Премьера была удачной. } \\
\text { - Я горжусь твоими успехами. }\end{array}$ & $\begin{array}{l}\text { аьтто, кхиам, толам, ларам } \\
\text { - Аьтто хуьлуш яц иза дахарехь. } \\
\text { - Цхьа а хІума ца хилира оцуьнах } \\
\text { - Прмьера аьтто болуш нисъели. } \\
\text { - Со воккхаве хьан кхиамех. }\end{array}$ \\
\hline $\begin{array}{l}\text { Die Errungenschaft - } \\
\text { - Ich zweifle nicht an der Errungenschaft. } \\
\text { - Sie müssen die modernen Errungenschaften } \\
\text { kennenlernen. }\end{array}$ & $\begin{array}{l}\text { - успех (достижение). } \\
\text { - Я не сомневаюсь в успехе. } \\
\text { - Вы должны познакомиться с современными дости- } \\
\text { жениями. }\end{array}$ & $\begin{array}{l}\text { - кхиам, толам } \\
\text { - Сан шеко яц толам хиларан. } \\
\text { - Шуна довза деза вайн заманан } \\
\text { кхиамаш. }\end{array}$ \\
\hline $\begin{array}{l}\text { Die Leistung - } \\
\text { - Die Leistung der Fußball- } \\
\text { manschaft waren nichts besonders. }\end{array}$ & $\begin{array}{l}\text { - успех (результат) } \\
\text { - Результаты футбольной команды были неважными. }\end{array}$ & $\begin{array}{l}\text { - жамl, кхиам,хилам } \\
\text { - Футболан командан хиламаш ледар дара. }\end{array}$ \\
\hline $\begin{array}{l}\text { Die Erholung - } \\
\text { - Er braucht Erholung. } \\
\text { - Sie ist zu Erholung in Sotschi. } \\
\text { - Erholung kenne ich nicht. }\end{array}$ & $\begin{array}{l}\text { - отдых } \\
\text { - Он нуждается в отдыхе. } \\
\text { - Он отдыхает в Сочи. } \\
\text { - Я не знаю отдыха. }\end{array}$ & $\begin{array}{l}\text { - садаlap, сацам } \\
\text { Иза садаlа дезаш ву. } \\
\text { - Иза Сочехь садоlуш ву. } \\
\text { - Сан сацам бац. }\end{array}$ \\
\hline
\end{tabular}




\section{ЛИТЕРАТУРА}

1. Примерная основная образовательная программа образовательного учреждения. Основная школа- М.: Просвещение, 2011. - 342 с. - (Стандарты второго поколения).

2. Общеевропейские компетенции владения иностранным языком: Изучение, обучение, оценка, Монография. — Страсбург; М.: Совет Европы, Департамент по языковой политике; МГЛУ, 2001-2003. — 259 с.

3. Абдукадырова Т.Т. Обучение немецкому языку в условиях чеченско-русского билингвизма/Монография - /LAPLAMBERT, Academic Publishing, Saarbrücken. 2011. 163c.

4. Абдукадырова Т.Т. Когнитивно-коммуникативный подход к обучению учащихся иноязычной абстрактной лексике в условиях чеченско-русского билингвизма (на основе трехъязычного словаря) [Текст]: автореф. дис. ... канд. пед. наук: 13.00.02/ Т.Т. Абдукадырова. - Ставрополь, 2009. - 23 с.

5. Барышников Н.В. Дидактический трилингвизм. // Н.В. Барышников. Теоретическая и экспериментальная лингводидактика (сборник статей). Пятигорск, 2003. - c.6-15.

6. Дешериев Ю.Д. Основные аспекты исследования двуязычия и многоязычия /Ю.Д. Дешериев, И.Ю. Протченко //Проблемы двуязычия и многоязычия:М.: Наука, 1972.С. $26-42$.

7. Колкер, Я.М. Роль родного языка в обучении иностранному / Я.М. Колкер // Иностр. языки в школе. 2004. - № 2. - С. 20-27.

8. Миньяр-Белоручев, Р.К. Механизм билингвизма и проблема родного языка в обучении иностранному // Иностр. языки в школе. - 1996. - № 5. - С. 15- 17

9. Махмудова А.Ж. Субординативная триглоссия как феномен, характеризующий современное языковое образование в многонациональных регионах Российской Федерации [Текст] // Филология и лингвистика в современном обществе: материалы IV Междунар. науч. конф. - М.: Буки-Веди, 2016. — C. 83-85.

10. Овхадов М.Р. Социально-лингвистический анализ чеченско-русского двуязычия: Автореферат дис. доктора филол. наук. М., 2001. - 40 с.

11. Тер-Минасова С.Г. Война языков и культур. М.: Слово/Slovo, 2008. - 344c.

12. Щерба Л.В. Преподавание иностранных языков в средней школе. Общие вопросы методики. - М.: Высшая школа, 1984. - 111 с.

13. Atkinson D. Teaching Monolingual Classes. - L: Longman, 1993.

14. Prodromou L. The Role of the Mother Tongue in the Classroom//IATEFL Issues, Issue 166, April-May 2002.

(с) Абдукадырова Тумиша Таштиевна (tumischa-uni@mail.ru).

Журнал «Современная наука: актуальные проблемы теории и практики»

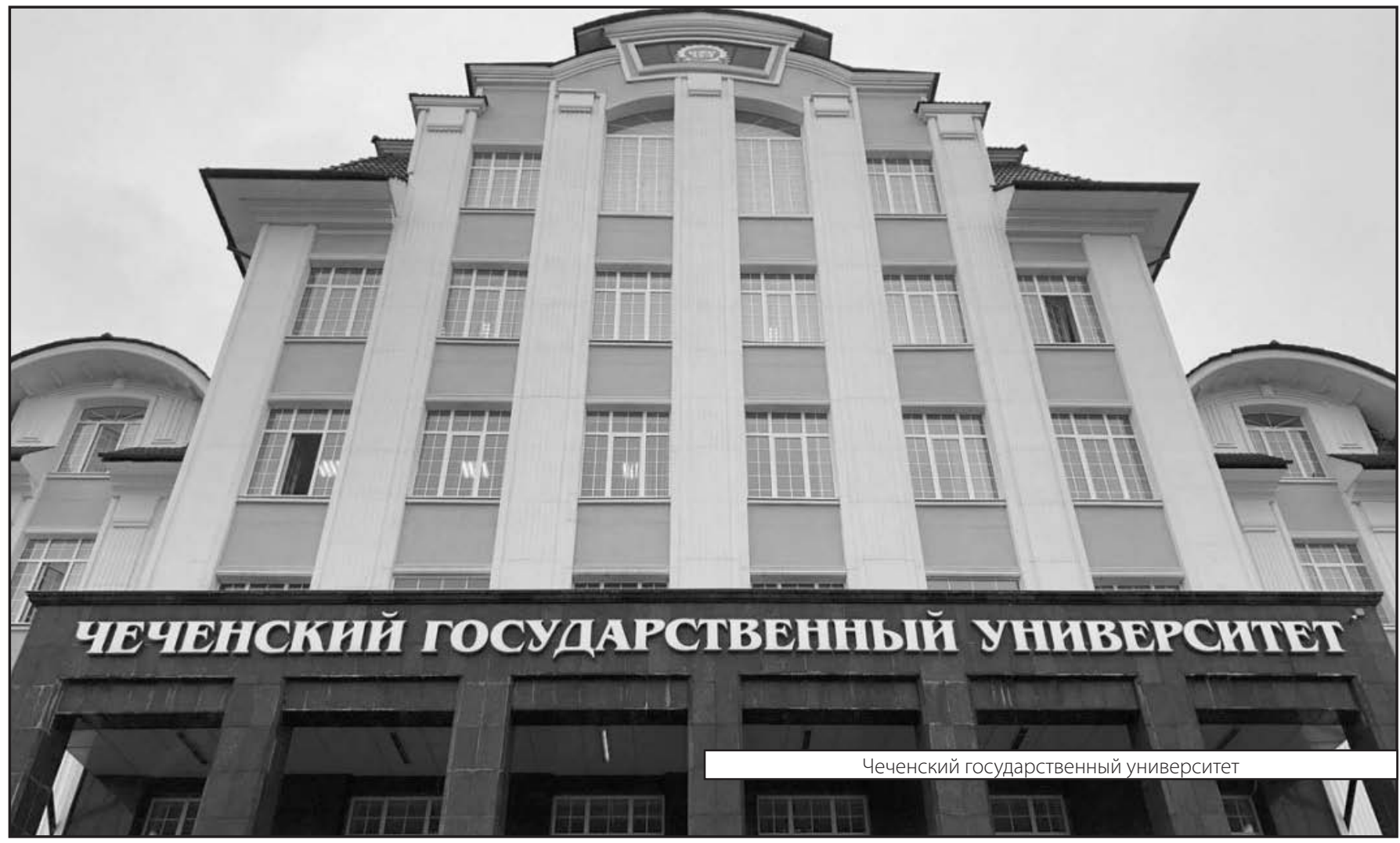

